\title{
TITLE: POSSIBLE MECHANISMS OF MACROLAYER FORMATION
}

\section{DISCLAIMER}

AUTHOR(S): P. Sadasivan

P. R. Chappidi

C. Unial

R. A. Nelson
This report was prepared as an account of work sponsored by an agency of the United States Government. Neither the United States (jovernment nor any agency thereuf, nor ary of their employees, makes any warranly, express or implied, or assumes any legal liability or responsihility for the accuracy, completeness, or usefulness of any information, apparatus, product, or process disclosed, or represents that its use would not infringe privately owned rights. Reference herein to any specific commercial product, process, or service by trade name, trademark, manufacturer. of otherwise does not necessarily constitute or imply its endorsement, recommendation, or favoring by the United States Government or any agency thereof. The views and opinions of authors expressed herein do not necessarily state or reflect those of the United States Government or any agency thereor.

\section{SUBMITTED To: The Enginooring Foundation Conference on Pool and External}

Flow Boiling

March 22-27, 1992

Santa Barbara, CA
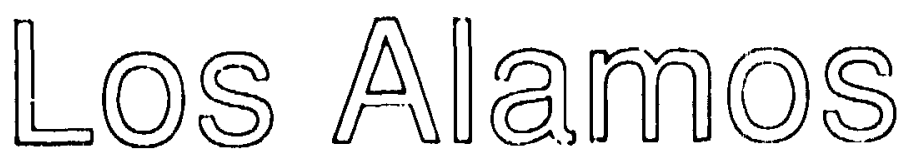


\title{
POSSIBLE MECHANISMS OF MACROLAYER FORMATION
}

\author{
by \\ P. Sadasivan, P.R. Chappidi, C. Unal, and R.A. Nelson \\ Los Alamos National Laboratory \\ Nuclear Technology and Engineering Division \\ Engineering and Safety Analysis Group \\ Los Alamos, NM 87545
}

\begin{abstract}
The high heat flux nucleate boiling region, also called the vapor mushroom region, has been shown to have a thin liquid layer on the heater surface under the large mushroom-shaped vapor bubbles that grow from the heater surface. The name given to this liquid layer is the macrolayer to differentiate it from the microlayer that exists under the discrete bubbles found at lower heat fluxes in the nucleate boiling region. Typical thicknesses of this macrolayer range from 50 to $500 \mu \mathrm{m}$ for water on a flat horizontal boiling surfä. .nd depend upon the heat flux. Thus, the macrolayer is thicker than the wedge-sh iped microlayers, found under discrete bubbles, which range in thickness from 1 to $10 \mu \mathrm{m}$. Although the mechanism of microlayer formation and its evaporation is conceptually simple that of the macrolayer is still not understood. This paper critically compares the potential mischanisms proposed for macrolayer formation. These mechanisms include the Helmholtz instability applied to the vapor stem above active nucleation sites, liquid trapped by lateral coalescence of discrete bubbles that initially form during the mushroom bubble's waiting period, and the limitation of liquid resupply at mushr(x)m departure as a result of vapor flcw from the active nucleation sites.
\end{abstract}




\section{INTRODUCTION}

There is currently a general consensus that fully developed pool nucleate boiling on a flat plate is characterized by the existence of a thin liquid layer immediately adjacent to the heater surface. This liquid layer is generally referred to as the macrolayer, to distinguish it from the rnicrolayer that exists under the base of individual nucleating bubbles. The first evidence of the macrolayer was presented by Gaertner and Westwater (1960), and by Gaertner $(1963,1965)$. Their results were based on extensive photography of the heater surface and the near-surface regions during pool boiling on a flat heater. They noted that the macrolayer contains numerous columns or stems of vapor. At short distances from the heater, they found that vapor stems from several adjacent active nucleation sites merged into a large vapor slu $u_{u}$. These large slugs have since been referred to as vapor mushrooins. The earliest sketch of the near-surface region in the vapor mushroom region of nucleate boiling was given by Gaertner and is reproduced below in Fig. 1.

Subsequent work by Kirby and Westwater (1965) provided additional evidence for the existence of the liquid layer underneath the vapor mushrooms.

The macrolayer configuration shown in Fig. 1 was idealized by Katto and Yokoya (1968) to have the form shown in Fig. 2. In the absence of further experimental results to deduce the $\mathrm{g}$ recise mechanism of formation and the internal structure of the macrolayer, this configuration has since been adopted widely in most analytical treatments of the macrolayer phenonienon."

The occurrence of the critical heat flux (CHF) has also been linked closely to the behavior of the macrolayer. Gaertner (1965) proposed that CHF occurred as a result of the collapse of the vapor stems because of hydrodynamic instabilities on

\footnotetext{
- Il should te pxinted out that several subseguent aralyses of the macrolayer have incorperatted refinements to account for additional factors of influence, while retaining the basic configuration shown in lige, 2
} 
their walls. He speculated that such a collapse of the stems would cause the formation of dry patches on the heater surface. In the discussion section of Gaertner's (1965) paper, Hsu pointed out that classical Helmholtz instability may not be applicable in this situation, because the predicted values were orders of magnitude higher than the thickness of the liquid layer observed by Kirby and Westwater (1965).

Katto and Yokoya (1968) proposed that the occurrence of $\mathrm{CHF}$ was the result of the consumption of the macrolayer due to evaporation. They noted that supply of liquid to the heater surface occurs only when the vapor mushroom detaches from the macrolayer. Immediately after the mushroom departs, fresh liquid is supplied to the heater surface, the macrolayer is reestablished, and a new vapor mushroom begins to grow above it. The time period between inception and departure of the mushroom is termed the hovering period of the mushroom. Thus Katto and Yokoya proposed that the heater surface would completely dry (and therefore CHF would occur) when the time required to evaporate the entire macrolayer is less than the hovering period of the vapor mushroom.

Ouwerkerk (1972) examined dry spot formation and growth on a flat heater, and concluded that the formation of localized dry patches, as a result of the evaporation of the liquid macrolayer, does not immediately lead to CHF. Some dry areas disappear shortly after being formed, and have no impact on $\mathrm{CHF}$. However, other diy spots were found to grow after being formed, leading to the CHF.

The above studies clearly established the importance of the macrolayer in the high heat flux nucleate boiling region, as well as in CHF. The next section presents a very brief overview o: selected quantitative measurements related to the macrolayer. 


\section{QUANTITATIVE DATA ON THE MACROLAYER THICKNESS}

The previously mentioned works of Gaertner (1965) as well as Katto and Yokcya (1968) provided limited quantitative data on the macrolayer. For example, Gaertner reported that both the vapor stem diameter and the macrolayer thickness varied as the square root of the heat flux. He also showed that the ratio of the macrolayer thickness to the vapor stem diameter was a constant and had a value of 0.6. Gaeriner measured the thickness of the macrolayer to be about $125 \mu$ at a heat flux of $300,000 \mathrm{Btu} / \mathrm{h} / \mathrm{ft}^{2}$. This data should perhaps be viewed as being only an approximate value, because it was inferred from photographs.

Katto and Yokoya (1976) used an alternative approach to obtain the thickness of the macrolayer. The test liquid was water and the the heatter was a $10-\mathrm{mm}$-diam copper plate. They used an interference plate at various distances above the heated surface and postulated that the plate would begin to affect the heat-transfer characteristics when the separation distance was approximately the same as the macrolayer thickness. They plotted the critical separation distance (or the macrolayer thickness) versus heat flux for the low heat flux nucleate boiling region. They then extrapolated their resuits to the high heat flux region and estimated that the macrolayer thickness near $\mathrm{CHF}$ was about $100 \mu$. This value must also be considered an approximate estimate.

Iida and Kobayasi (1968) studied water boiling on a 20-mm-diam copper heater. They obtained more accurate data on the macrolayer thickness by using a conductivity probe to make local time-averaged void traction measurements at various points above the heater surface. For different horizontal planes located between 25 and $500 \mu$ above the heater surface, they measured the void fractions at various locations on the plane. They then calculated the spatial standard deviation of the void fraction at each vertical distance; they designated the upper boundary of the macrolayer as the distance at which the variation of the standard deviation with 
height above the heater changes dramatically. Above this boundary, the standard deviation of the void fraction showed little change with height. Below this plane, the standard deviation increased linearly as the height decreased. Using this method, they determined macrolayer thicknesses of about $460 \mu$ at CHF. The diameter of the conductivity probe was $40 \mu$; it is likely that their void fraction measurements close to the CHF may be in error, because the average size of the active nucleation site is less than the diameter of the probe.

Bhat et al. (1986) carried out a set of experiments similar to those of lida and Kobayasi. They boiled distilled water on a copper heater, $42 \mathrm{~mm}$ in diameter, and polished with a 4/0 emery grade paper. The diameter of the conductivity probe was $60 \mu$, so their results may have the same drawback as those of Iida and Kobayasi with respect to the surface void fraction. They measured the frequency of vapor contact on the probe as a function of the height above the heater surface; they designated the upper boundary of the macrolayer as the point at which the frequency of vapor contact drops precipitously to very low levels. Their method yielded a macrolayer thickness of about $65 \mu$ close to CHF.

$\mathrm{Yu}$ and Messler (1977) provided an indirect estimate of the macrolayer thickness based on their fool boiling experiments with water on a 8-mm-diam Chromel I' disk. By employing a quick-response thermocouple located at the center of the heater surface and flush with it, Yu and Messler obtained a trace of the rapid temperature fluctuations on the heater surface. They related the experimental traces of time periods of relatively constant surface temperature immediately preceding a sudden increase in the temperature to the theoretical time required to completely evaporate the macrolayer. Based on this analysis, they estimated macrolayer thicknesses of less than $16 \mu$.

Haramura (1987) estirnated the macrolayer thickness using a method similar to that of Yu and Messler (1977); however, while Yu and Messler tracked the surface 
temperature fluctuations, Haramura tracked heat flux variations for a constant heater surface temperature. Based on simultaneous photography and heat flux measurements, he noted that the heat flux begins to increase when the heater surface is covered by more than one coalesced bubble. This increase is sustained for a short duration. He attributed the increase in heat flux to the existence of a liquid macrolayer beneath the bubble. When this liquid layer thickness decreases as a result of evaporation, the heat flux increases. The heat flux would begin to decrease when the liquid layer dried out completely. Based on heat flux time series data, Haramura estimated that the time elapsed between formation and dryout of the macrolayer was $13 \mathrm{~ms}$ for a heat flux of $23 \mathrm{~kJ} / \mathrm{m}^{2}$. Then an energy balance yielded a macrolayer thickness of $11 \mu$.

As is clear from the preceding discussion, the eduction of the macrolayer structure by experimental means has yielded widely different values of the layer thickness from one experiment to another. Some of the discrepancies can be attributed to differences in heater surface roughness (which in turn affects nucleation :"te density), differences in surface wettability (which could potentially affect the vapor stem structure), and differences in heater characteristic dimensions (which affect the liquid resupply mechanism to the macrolayer following departure of the mushroom). However, the fact that different investigators have used largely different techniques to infer (or indirectly measure) the macrolayer thickness could also have a significant effect on the results.

Despite the availability of limited experimental data on the thickness of the macrolayer, there is currently no consensus as to the precise mechanism of formation of the macrolayer. About all that appears to be certain about the process of formation of the macrolayer is that it is an extremely fast phenomenon, taking at most a few miliiseconds. This was inferred by Kallo and Yokoya (1968) from their photographic studies. However, several key aspects of the macrolayer formation 
process remain unresolved. What factors determine the thickness of the macrolayer? What is the internal structure of the macrolayer-the relation between the vapor stem diameter and the size of the cavity that feeds the stem? Clearly these issues can be resolved if a realistic description of the mechanism of macrolayer formation process were formulated.

\section{POSSIBLE MECHANISMS}

Having discussed the various atteinpts to characterize the macrolayer quantitatively by experimental means, we will next examine the mechanisms that have been proposed to describe the mechanism of formation of the macrolayer. These include the Helmholtz instability description of Haramura and Katto (1983), and the vapor stern coalescence model of Bhat et al. (1983). We will then introduce two additional approaches that could potentially be used to characterize the macrolayer formation process. One of these is a bubble coalescence model and the second is ? mechanism that is related to the limitations imposed on the resupply of liquid to the rear-h eater surface following the departure of the vapor mushroom.

\section{HELMHOLTZ INSTABILITY ON VAPOR STEM WALLS}

The first physical model for the macrolayer was proposed by Haramura and Katto (1983). They postulated that the maximum thickness of the macrolayer, when it is reestablished upon the departure of the mushroom, is limited by hydrodynamic instabilities at the interface along the vapor stem walls. Haramura and Katto derived an expression for the Helmholtz unstable wavelength for the vapor stem configuration, and then arbitrarily assumed that the maximum macrolayer thickness was a fourth of this wavelength. Their expression for the macrolayer thickness is 


$$
\delta=\frac{\pi}{2} \sigma \frac{\rho_{f}+\rho_{g}}{\rho_{f} \rho_{g}}\left[\frac{A_{v}}{A_{w}}\right]^{2}\left[\frac{\rho_{g} h_{f g}}{q^{\prime \prime}}\right]^{2}
$$

They used the following expression for the heater void fraction $\frac{A_{v}}{A_{w}}$ :

$$
\frac{A_{v}}{A_{w}}=0.0584\left[\frac{\rho_{g}}{\rho_{f}}\right]^{0.2}
$$

Subsequently, Pasamehmetoglu and Nelson (1987) showed that the Helmholtz instability approach could predict the macrolayer (water) data of Bhat et al. (1983) if the following expression were used to calculate the heater void fraction:

$$
\frac{A_{v}}{A_{W}}=6.206 \times 10^{-4} q^{\prime 0.25}
$$

Although Eq. (3) suggests that the Helmholtz instability model for the macrolayer thickness is a viable description of the process, there are several aspects of this model that are subject to debate:

- Can this type of an interfacial instability occur as close to the boundary as is postulated?

- As is now widely accepted, surface wettability has a fairly pronounced effect on the nucleate boiling characteristics; yet, a purely hydrodynamic model, Eqs. (1) and (2), derived on the basis of countercurrent flow, would be unable to account for this effect.

- Some studies indicate that the heater surface void fraction is rather low (less than $5 \%$ ) at heat fluxes close to the critical value. This implies that the vapor stem spacing is considerably high. Under these circumstances, 
even assuming that the Helmholtz instability dictates the height of the vapor stems, it is difficult to visualize how this would force the thickness of the liquid portion of the macrolayer to attain the same value.

Two recent studies provide bases for additional arguments against the applicability of Eq. (1) toward the prediction of CHF in pool boiling situations. These are discussed below.

\section{Wang and Dhir (1991)}

This study investigated the pool boiling of water on a vertical flat plate. Wang and Dhir made careful measurements of the nucleation site density and the active site density on the heater surface. This was done for contact angles of $90^{\circ}, 35^{\circ}$, and $18^{\circ}$. Here, we will confine our discussion to the case of $\beta=90^{\circ}$ only. For this case, Wang and Dhir obtained a peak heat flux of $0.61 \mathrm{MW} / \mathrm{m}^{2}$ and the corresponding wall superheat to be $20^{\circ} \mathrm{C}$. At this heat flux, Eq. (3) predicts a heater surface void fraction $\frac{A_{v}}{A_{h}}$ of $1.735 \%$. Also, the ideal bubble solution of Katto and Yokoya (1976) for the hovering period, $\tau_{d}$, of the vapor mushroom,

$$
\tau_{d}=\left[\begin{array}{c}
3 \\
4 \pi
\end{array}\right]^{0.2}\left[\frac{2.75 \rho_{f}+4 \rho_{g}}{g\left(\rho_{f}-\rho_{g}\right)}\right]^{0.5}\left[\begin{array}{c}
A_{h} q \\
\rho_{g} h_{f g}
\end{array}\right]^{0.2}
$$

yields a value of $109 \mathrm{~ms}$ in this case. At CHF, the minimum requirement" is that the macrolayer must evaporate completely in one hovering period of the vapor mush-

\footnotetext{
"Actually, Unal et al. (1991) argue that the evaporation of the macrolayer, and therefore the occurrence of a dry spot on the heater surface, need not immediately cause CHF. We will discuss this issue later in this paper.
} 
room. Under these conditions, an energy balance on the macrolayer can be written as

$$
<q>\tau_{d}=\delta \rho_{f} h_{f g}\left[1-\frac{A_{v}}{A_{h}}\right] .
$$

Using $A_{v} / A_{h}$ and $\tau_{d}$ values from above, and with $\left\langle q>=q C H F=0.61 \mathrm{MW} / \mathrm{m}^{2}\right.$, and using the appropriate values of the properties of water, we get a macrolayer thickness of $30 \mu$. Even accounting for the uncertainty in the evaluation of the void fraction, we find that a void fraction of as high as $60 \%$ would imply a macrolayer thickness of no more than $75 \mu$. However, the Helmholtz instability approach, Eq. (1) yields a macrolayer thickness of $2.28 \mu$ for a void fraction of $1.735 \%$. If the thickness of the macrolayer is dictated by Helmholtz instability considerations, the macrolayer would simply not dry up in one hovering period of the vapor mushroom. Consequently, heater surface dry patches, which several studies indicate are the necessary precursors of the occurrence of $\mathrm{CHF}$, would never form.

\section{Unal et al. (1991)}

In their analytical study of dry patch formation, Unal et al. (1991) determined that the occurrence of the dry patch alone would not automatically lead to CHF. To reach the CHF condition, the temperature at the center of the dry patch must first exceed a certain critical value above which liquid-solid contact would be precluded. When this condition is reached, the hot spot is sustained for periods beyond one hovering period, growing to eventually blanket the surface in a power-controlled experiment. Therefore, estimating the macrolayer thickness based on an energy balance such as in Eq. (5) would give the maximum possible surface-averaged value for the macrolayer thickness In reality, the thicknesses would have to be lower at 
areas where dry patches would form. Indeed, the Unal et al. (1991) analyses yieided upper bounds on the macrolayer thickn sss of less than $11 \mu$ in the regions where the dry spots occur. This is far less than the values that would be predicted by the Helmholtz instability approach.

Based on the preceding discussion, we believe that the Helmholtz instability mode! suffers from serious shortcomings. A final judgment as to whether such an approach, after sufficient refinements, can ever be used as a predictive tool in this situation, will have to await the experimental resolution of the dynamics of the macrolayer formation process. For the moment, we can only state that with the present knowledge of the macrolayer, this approach does not seem a viable approach.

\section{LATERAL COALESCENCE OF VAPOR STEMS}

The fundamental premise of this model, proposed by Bhat et al. (1983), is that the macrolayer formation is related to the lateral coalescence of adjacent vapor stems (Fig. 3). They suggested that the area of the vapor stem associated with an active nucleation site increases as a result of the vertical coalescence of successive bubbles emitted from the site, as well as i result of evaporation at the stem walls from heat transfer from the surrounding liquid. They argued that the macrolayer thickness would be equal to the height above the heater suriace at which the vapor stems merged laterally with each cther. Based on an analysis of the evaporative and bubble coalescence effects, they derived an expression for the macrolayer thickness. Their final equation for the macrolayer thickness contains numerous experimentspecific parameters. They used results from various studies, carried out under widely different experimental conditions, to obtain relations for these unknown parameters. It is very likely that in doing so, they introduced considerable uncel tainty in to their final results. As with the Helmholtz instability approach, this model also does not account for contact angle effects. Despite these shortcomings, 
the notion that the mechanism of macrolayer formation is related to the coalescence of vapor structures, seems highly plausible.

\section{LATERAL COALESCENCE OF BUBBLES}

Relating the process of macrolayer formation to the lateral coalescence of individual bubbles themselves is a simplification of the lateral coalescence model discussed in the preceding section. Studies of nucleation site densities in high heat flux boilin:; (Gaertner 1963, Wang and Dhir 1991, etc.) have clearly estailished that the active site density increases by several orders of magnitude as we approach $\mathrm{CHF}$ from the low heat flux nucleate boiling region. This increases the possibility that bubbles growing at neighboring active sites can coalesce laterally at a certain stage during the growth fhase and before they depart from the surface. Then, a certain volume of liquid will be trapped between the vapor bubbles below the plane of coalescence of the bubbles. Above that plane, the vapor bubbles from several neighboring sites will merge to generate the vapor mushroom. Experimental evidence to this effect was recently provided by Williamson and El-Genk (1991). In their highspeed photographic studies of pool boiling of water on a flat plate, they observed that as the heat flux was increased, the growth of bubbles from adjacent sites led to interference between the bubbles and eventually to bubble coalescence.

As a first approximation, we idealize the cavities to have a uniform size, and to be uniformly distributed over the heater surface as shown in Fig. 4. Then if $r_{b}$ is the radius of each bubble at the instant lateral coalescence occurs, $r_{b}$ is related to the total number of cavities, $n$, by

$$
\begin{aligned}
4 r_{b^{2}} n & =A_{h} \text { or } r_{b}=0.5\left(A_{h} / n\right)^{0.5} \\
r_{b} & =0.5 N_{A}^{-0.5} .
\end{aligned}
$$


If $\beta$ is the contact angle, each bubble makes contact with the heater surface over a circle of radius $r_{b} \sin \beta$. Also, the height of the bubble center above the heater surface is $r_{b} \cos \beta$. Thus the total volume of the vapor and liquid below the plane of lateral coalescence is that of a square of side $2 r_{b}$ and height equal to $r_{b} \cos \beta$. Out of this volume of $4 \mathrm{rb}^{3} \cos \beta$, the volume of the vapor is equal to the volume of the hemisphere minus the volume of the spherical cap of height $\left(r_{b}-r_{b} \cos \beta\right)$. This gives the volume of vapor below the plane of coalescence as

$$
\frac{2}{3} \pi r^{3}-\left[\frac{1}{3} \pi r_{b}^{3}\left[2+\cos ^{3} \beta-3 \cos \beta\right]\right]
$$

which simplifies to $\left[\frac{1}{3} \pi r_{b}^{3}\left[3 \cos \beta-\cos ^{3} \beta 1\right]\right.$. Then, we get the volume of liquid trapped bulow the plane of coalescence as

$$
4 r_{b}^{3} \cos \beta-\left[\frac{1}{3} \pi r_{b}^{3}\left[3 \cos \beta-\cos ^{3} \beta\right]\right] .
$$

Clearly this liquid is not spread uniformly over the heater surface. It is confined to the four corners of the aiea of influence of each bubble. The maximum thickness of the liquid layer is equal to the heigiti of the plane of coalescence above the heater surface (equal to $x_{h} \cos \beta$ ) and is zero at the periphery of the bubble contact area on the heater surface. However, we can calculate an equivalent thickness, $\delta$, of the macrolayer by id:alizing that the macrolayer is spread uniformiy over the heater surface to conform with the configuration shown in Fig. 2. Then, we get

$$
\left.\delta=\pi, \cos \beta-\frac{\pi}{12}\left[3 \cos \beta-\cos ^{3} \beta\right]\right] .
$$


Recently Wang and Dhir (1991) provided nucleation site density measurements during pool boiling of water. They found that the active site density varies as $\mathrm{q}^{2.0}$. The proportionality constant was found to depend strongly on the contact angle. The following expressions correlate the data of Wang and Dhir for contact angle values of $35^{\circ}$ and $18^{\circ}$ when $q$ is expressed in $W / \mathrm{cm}^{2}$ :

$$
\left.\begin{array}{l}
N_{A}=0.0567 q^{2} \text { for } \beta=35^{\circ} \\
N_{A}=0.0116 q^{2} \text { for } \beta=18^{\circ}
\end{array}\right\} \text {. }
$$

By substituting Eqs. (10) and (6) into (9), we obtain a relation between the heat flux, q, and the macrolayer thickness, $\delta$. Figure 5 shows i plot of $\delta$ versus the surface heat flux for contact angles of $35^{\circ}$ and $18^{\circ}$. We can make several observations from this figure:

- First, the macrolayer thickness decreases as the contact angle increases. It is well known that the CHF decreases as the contact angle increases. Heater surface dry patches, which are the precursors of CHF, form in relatively shorter time periods when the macrolayer is thinner. Therefore, the trend in macrolayer thickness with contact angle predicted by this preliminary lateral coalescence model appears to be physically correct.

- One merit of this lateral coalescence model is that it is the first to consider contact angle effects on the macrolayer formation process. However, in its present form, it suffers from the obvious drawback that the model works only for contact angles less than $90^{\circ}$. This ca: be seen by noting that fic. (9) predicts $\delta=0$ when $\beta=9()^{\circ}$. This points to the need for further refinement of this model. We present the model here only it the context of a prelim- 
inary report. However, below $90^{\circ}$, the model predicts the right trend-as the contact angle decreases, the plane of lateral coalescence is further away from the heater surface, and more liquid is trapped between the bubbles. Consequently, the equivalent macrolayer thickness increases.

- This model assumes that the bubble undergoes no deformation as it grows. This is not sufficiently validated. In fact, Williamson and El-Genk (1991) indicates that each bubble may be attached to the wall through a slender neck-like column. Then the plane of coalescence is further above the heater surface than is assumed here. Also, the heater surface area void fraction will be less than predicted by this model. But, as Katto and Yokoya (1968) point out, the time between departure of one mushroom and the inception of the next is of the order of a few milliseconds in the high heat flux region; therefore, the necking effect can be expected to be minimal at heat fluxes close to CHF.

Figure 6 is a comparison of I:da and Kobayasi's experimental measurements of the average macrolayer thickness with the equivalent thickness predicted by the present lateral coalescence model. The data agrer closely with the predicted values corresponding to $\beta=0^{\circ}$. However, the experimental data were obtained with water on a copper heater, and therefore the contact angle should be considerably highes , an $0^{\circ}$ in reality.

It is clear that the simple lateral coalescence model presented here, despite its advantage of accounting for weltability effects, has numerous shortconings in its present form. Therefore, this model must necessarily be considered to be in its initial stage. These shortcomings notwithstanding, it predicts the trends reasonably well when compared with available nuclea "on site density data. When cavity size variations, and conseguently bubble size variations, as well as non-uniform cavity 
spacings, are included in the model, it will be able to account for possible spatial variations in the macrolayer thickness. Upon further refinement, this model appears to have the potential to describe the macrolayer formation process accurately.

\section{STEM VAPOR VELOCITY-LIMITED MACROI.AYER}

We make use of Wang and Dhir's (1991) data to explore another possible inechanism of macrolayer formation. Based on their experimental measurements of active sites, Wang and Dhir (1991) proposed the following correlations for the cumulative active site density, $\mathrm{N}_{A}$ in sites $/ \mathrm{cm}^{2}$, as a function of the cavity diameter $D_{c}$ in microns.

$$
\therefore A= \begin{cases}4.5 \times 10^{4} \exp \left(-1.35 D_{C}\right) & \text { for } D_{c}<5 \mu \\ 4.0 \times 10^{4} D_{C}-4.2 & \text { for } D_{C}>5 \mu\end{cases}
$$

Warig and Dhir's results indicate that for $\beta=90$ degrees, the diameter of the active cavities ranged from about $3.3 \mu$ to about $15 \mu$. The cumulative active site density corresponding, to cavity diameters from 3.3 to $15 \mu$, in steps, $\Delta D$, of $0.25 \mu$, was determined using lic. (11). As the cavity diameter is decreased from $D_{1}$ to $D_{1} \cdot \Delta D$, there are $N_{1}$ additional sites that breme active. In reality, these cavities have diameters between $D_{1}$ and $D_{1}-\Delta !$ ). However, as an approximation, we assumed that this represents $N$, cavities of size $\left.D_{1}-\Delta I\right) / 2$. This we get the number density of cavities with diameters ranging from $3.4 \mu$ to 15.00$) \mu$, as listed in Table I.

Then lice heater surface area void fraction can be calculated by summing the area of all the active cavities on the surface. The final entry in column 3 of Table 1 shows that this calculation yields a void fraction of $0.7945 \times 10^{-4}$. This calculation is based on the assumption that each vapor stern has the same radius as the cavity that 
feeds into it. However, in gentral, it is reasonable to expect that the stem radius will be considerably greater than the cavity radius. Chappidi et al. (1991) found that the stem radius was 25 times tha radius of the active cavity. In Wang and Dhir's data, we can estimate this factor by comparing the area void fraction cited above with that predicted by the Pasamehmetoglu and Nelson correlation, Eq. (3). This method yields

$$
\mathrm{r}_{\text {stem }}=14.8 \mathrm{r}_{\text {cav }} \text { or } \mathrm{k}=\frac{\mathrm{r}_{\text {stem }}}{\mathrm{r}_{\mathrm{cav}}}=14.8
$$

Assuming that the factor $k$ is approximately the same for all the cavities regardless of their size," and that the triple point evaporation phenomenon accounts for the entire heat transfer," we can write the overall energy balance as

$$
m_{\mathrm{e}} 2 \pi k \Delta \mathrm{Th} \mathrm{h}_{\mathrm{g}} \sum_{\text {all cavitics }}\left(\mathrm{r}_{\mathrm{c}}\right)_{\mathrm{i}}=\left\langle\mathrm{q}^{\prime \prime}>A_{\mathrm{h}} .\right.
$$

Using the data in Table I, Eq. (14) yields a value of $m_{c}$ equal to $1.2157 \times 10^{-5} \mathrm{~kg} / \mathrm{m} \mathrm{s}^{\circ} \mathrm{C}$. For a single stem, the total vapor generation rate is (subject to the second assumption above) $m_{c} \pi d_{s t c m} \Delta T$. Then, the average vapor velocity in the stem is

$$
v_{\text {vapor }}=\frac{m_{0} \pi d_{\text {stem }} \Delta T}{\rho_{g} \pi d_{s t e m} / 4}
$$

\footnotetext{
-Although we can expecl $k$ t: be a function of the contact angle and the heat flux, its dependence on the cavity diamefer is less clear, so this assumption is subjert to debate.

"This is a reasumable assumption. Previous studies (Chappidi el al. 1991, for example) have shown that the triple perint evaporation accounts for most of the heat transfer. Contributions from steminferface cvapuration and macrolayer evapuration were shown to be small.
} 
Calculations of the vapor velocity based on Eq. (8) are listed in Table I. These calculations suggest that fairly high vapor velocities are possible in the vapor stemsthe velocities range from $32.4 \mathrm{~m} / \mathrm{s}$ for the smallest cavity to $7.3 \mathrm{~m} / \mathrm{s}$ for the largest cavity. These vapor velocities suggest two possible ways in which the macrolayer formation process can be affecied.

First, this suggests that if enough smiall cavities are located contiguously, this could lead to a local area of high vapor velocity into the overlying mushroom. This then has the potential of distorting the vapor mushroom, leading to the possibility of localized disruption of the liquid resupply mechanism to reestablish the macrolayer.

A second possible effect of the high vapor velocities is that it ensures that the time elapsed from the departure of one vapor mushroom to the initiation of the nex، is very small. Once a new vapor mushroom begins to form, further liquid resupply to the macrolayer is inhibited by the mushroom. Then this is another possible mechanism for the formation of the macrolayer.

In both the above scenarios, the effect of the disruption of the resupply of liquid to the macrolayer is that local thicknesses of the macrolayer will now be set by this condition rather than by the conventional mechanism. It is also apparent that if disruption in the liquid resupply is responsible for imposing localized limits on the thickness, it will account for the local thin regions previously suggested by Unal et al. (1991) that are crucial in the development of the hot-spot controlled model for CHF. It appears then that the mechanism, if it does occur, will do so in conjunction with the mechanism that dictates the thickness of the macrolayer over the remainder of the heater surface. Experimental measurements of liquid flow patterns close to the heater surface will perhaps reveal the extent to which liquid-resupply is a factor in determining the macrolayer thickness. This issue needs further investigation. 


\section{SUMMARY}

In this paper, we have presented a short description of the possible mechanistic explanations for the formation of the macrolayer during pool boiling on a flat plate. We believe that the Helmholtz instability approach does not now appear to be the main factor in determining the macrolayer thickness. We also introduce the rudiments of a simple lateral bubble coalescence model, which appears to show promise in being able to describe the macrolayer formation process correctly. This model has the added advantage that it accounts for surface wettability effects as well. A final resolution of the mechanism of macrolayer formation appears to turn on the availability of detailed experimental measurements of vapor and liquid flow patterns close to the heater surface.

\section{REFERENCES}

Bhat, A.M., Prakash, R., and Saini, J.S., 1983, "On the Mechanism of Macroliyer Formation in Nucleate Pool Boiling at High Heat Fluxes," Int. J. Heat Mass Transfer, 20, pp. 735-740.

Bhat, A.M., Saini, J.S., and Prakash, R., 1986, "Role of Macrolayer Evaporation in Pool Boiling at High lleat Flux," Int. J. Heat Mass Transfer, 29, pp. 1953-1961.

Chappidi, P.R., Unal, C., Pasamehmetoglu, K., and Nelson, R.A., 1991, "On the Relationship Between the Macrolayer Thickness and the Vapor Stem Diameter in the High Heat Flux Nucleate Pool Boiling Region," Int. Connm. Heat and Mass Transf(er, 18, pp. 19.5-20.5. 
Gaerner, R.F., 1965, "Photographic Study of Nucleate Pool Boiling on a Horizontal Surface," ASME Journal of Heat Transfer, 87, pp. 17-29.

Gaertner, R.F., 1963, "Distribution of Active Sites in the Nucleate Boiling of Liquids," Chem. Engr. Prog. Symn. Ser., 59, pp. 52-61.

Gaertner, R.F., and Westwater, J.W., 1960, "Population of Active Sites in Nucleate Boiling Heat Transfer," Chem. Engr. Prog. Symp. Ser., 56(30), pp. 39-48.

Haramura, Y., and Katto, Y., 1983, "A New Hydrodynamic Model of Critical Heat Flux, Applicable Widely to Both Pool and Forced Convective Boiling on Submerged Bodies in Saturated Liquids," Int. J. Heat Mass Transfer, 26, pp. 389-399.

Iida, Y., and Kobayasi, K., 1969, "Distributions of the Void Fraction Above a Horizontal Heating Surface in Pool Boiling," Bulletin of the JSME, 12, pp. 283-290.

Katto, Y., and Yokoya, S., 1968, "Principal Mechanism of Boiling Crisis in Pool Boiling," Int. J. Heat Mass Transfer, 11, pp. 993-1002.

Kirby, D.B., and Westwater, J.W., 1965, "Bubble and Vapor Behavior on a Heated Horizontal Plate During Pool Boiling Near Burnout," Chem. Engr. Prog. Symp. Ser., 61, pp. 238-248.

Ouwerkerk, H.J., 1972, "Burnout in Pool Boiling: The Stability of Boiling Mec'lanisms," Int. J. Heat Mass Transfer, 15, pp. 25-34. 
Pasamehmetoglu, K., and Nelson, R.A., 1987, "The Effect of Helmholtz Instability on the Macrolayer Thickness in Vapor Mushroom Region of Nucleate Pool Boiling," Int. Comm. Heat Mass Transfer, 14, pp. 709-720.

Unal, C., Daw, V., and Nelson, R.A., 1991, Unifying the Controlling Mechanisms for the Critical Heat Flux and Quenching: The Ability of Liquid to Contact the Hot Surface," Los Alamos National Laboratory docliment LA-UR-91-933.

Wang, C.H., and Dhir, V.K., 1991, "Effect of Surface Wettability on Active Nucleation Site Density During Pool Boiling of Water on a Vertical Surface," Presented at the 1991 National Heat Transfer Conference, Minneapolis. MN, July 1991, HTD-Vol 159, pp. 89-96.

Williamson, C.R., and El-Genk, M.S., 1991, "High-Speed Photographic Analysis of Saturated Nucleate Pool Boiling at Low Heat Flux," Paper presented at the 1991 ASME Winter Annual Meeting, Atlanta, GA.

Yu, C-L., and Messler, R.B., 1977, "A Study of Nucleate Boilin $n_{i}$ Near the Peak Heat Flux through Measurement of Transient Surface Temperature," Int. J. Heat Mass Transfer, 20, pp. 827-840. 
TABLE I

CALCULATIONS BASED ON WANG AND DHIR'S (1991) ACTIVE SITE DATA FOR WATER ON COPPER

\begin{tabular}{|c|c|c|c|}
\hline $\begin{array}{c}\text { Cavity Diameter } \\
\text { (microns) }\end{array}$ & $\begin{array}{c}\text { Number of Sites } \\
\text { per } \mathrm{cm}^{2}\end{array}$ & $\begin{array}{c}\text { Cumulative Area } \\
\text { of Cavities } / \mathrm{cm}^{2}\end{array}$ & $\begin{array}{l}\text { Vapor Velocity } \\
\text { on Stem }(\mathrm{m} / \mathrm{s})\end{array}$ \\
\hline 3.400000 & 249.7 & $2.2672855 e-5$ & 32.40680 \\
\hline 3.800000 & 145.6 & $3.9177132 \mathrm{e}-5$ & 28.99556 \\
\hline 4.200000 & 84.8 & $5.0926348 \mathrm{e}-5$ & 26.23408 \\
\hline 4.6001000 & 49.2 & $5.9139453 e-5$ & 23.95285 \\
\hline 5.000000 & 29.7 & $6.4967186 e-5$ & 22.03662 \\
\hline 5.400001 & 10.5 & $6.7377099 e-5$ & 20.40428 \\
\hline 5.800001 & 7.25 & $6.9292524 e-5$ & 18.99709 \\
\hline 6.200001 & 5.1 & $7.0838614 \mathrm{e}-5$ & 17.77147 \\
\hline 6.600001 & 3.7 & $7.2103532 e-5$ & 16.69441 \\
\hline 7.000001 & 2.7 & $7.3150783 e-5$ & 15.74044 \\
\hline 7.400001 & 2.0 & $7.4027019 e-5$ & 14.88961 \\
\hline 7.800001 & 1.6 & $7.4767122 \mathrm{e}-5$ & 14.12604 \\
\hline 8.200001 & 1.2 & $7.5397562 \mathrm{e}-5$ & 13.43697 \\
\hline 8.600000 & 0.93 & $7.5938726 e-5$ & 12.81199 \\
\hline 9.000000 & 0.74 & $7.6406497 \mathrm{e}-5$ & 12.24257 \\
\hline 9.400000 & 0.59 & $7.6813412 . e-5$ & 11.72161 \\
\hline 9.799999 & 0.47 & $7.7169461 e-5$ & 11.24318 \\
\hline 10.20000 & 0.38 & $7.7482669 \mathrm{e}-5$ & 10.80227 \\
\hline 10.60000 & 0.31 & $7.7759563 e-5$ & 10.39464 \\
\hline 11.00000 & 0.26 & $7.8005469 e-5$ & 10.01665 \\
\hline 11.40000 & 0.22 & $7.8224788 \mathrm{e}-5$ & 9.665189 \\
\hline 11.80000 & 0.18 & $7.8421173 e-5$ & 9.337555 \\
\hline 12.20000 & 0.15 & $7.8597666 e-5$ & 9.031406 \\
\hline 12.60000 & 0.15 & $7.8756835 e-5$ & 8.744695 \\
\hline 13.00000 & 0.11 & $7.8900848 e-5$ & 8.475628 \\
\hline 13.40000 & 0.09 & $7.9031539 \mathrm{e}-5$ & 8.222624 \\
\hline 13.80000 & 0.08 & $7.9150479 e-5$ & 7.984287 \\
\hline 14.20000 & 0.07 & $7.9259022 e-5$ & 7.759378 \\
\hline 14.59999 & 0.06 & $7.9358324 e-5$ & 7.546793 \\
\hline 14.99994 & 0.05 & $7.9449 .397 e^{3-5}$ & 7.345545 \\
\hline
\end{tabular}




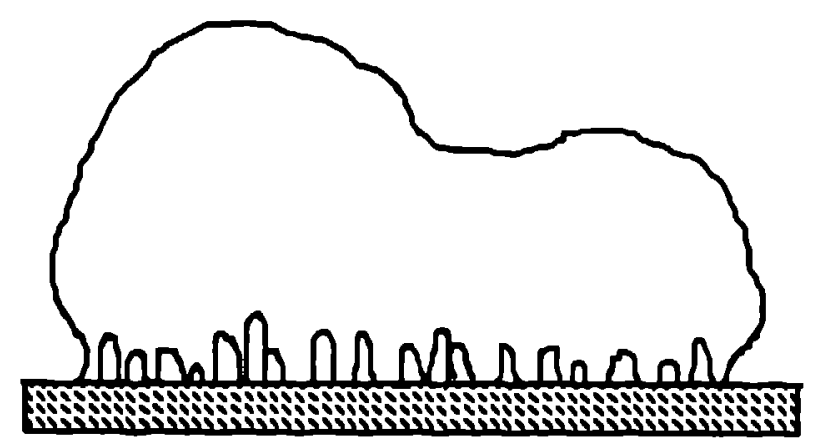

Fig. 1.

Vapor mushroom and vapor stems in macrolayer (Gaertner 1965).

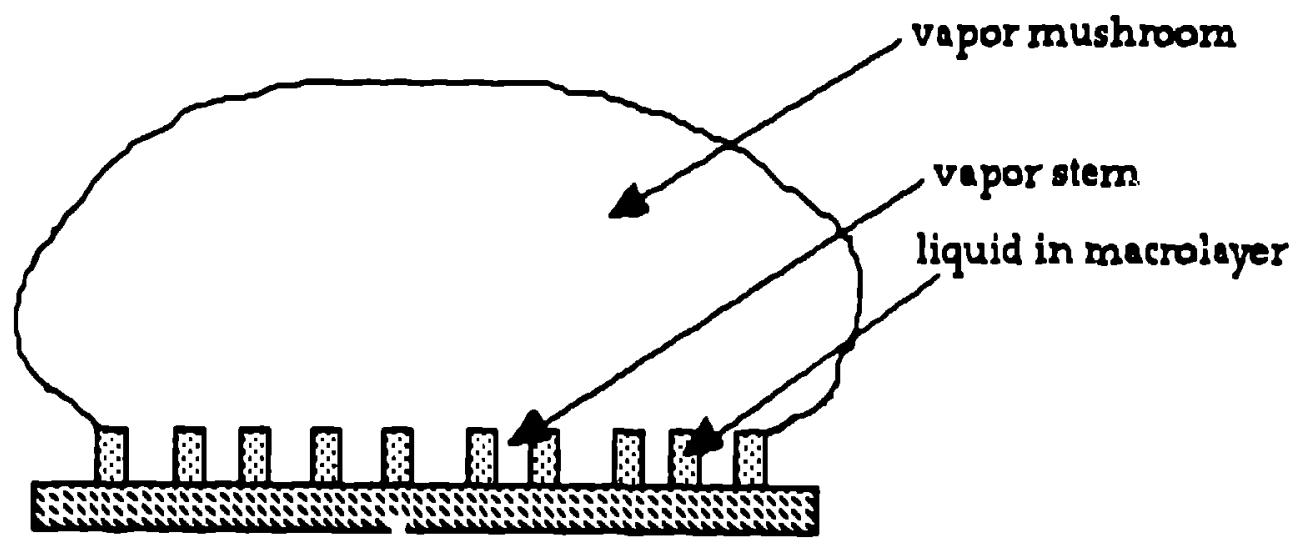

Fig. 2.

Idealized sketch of vapor mushroom and macrolayer. 


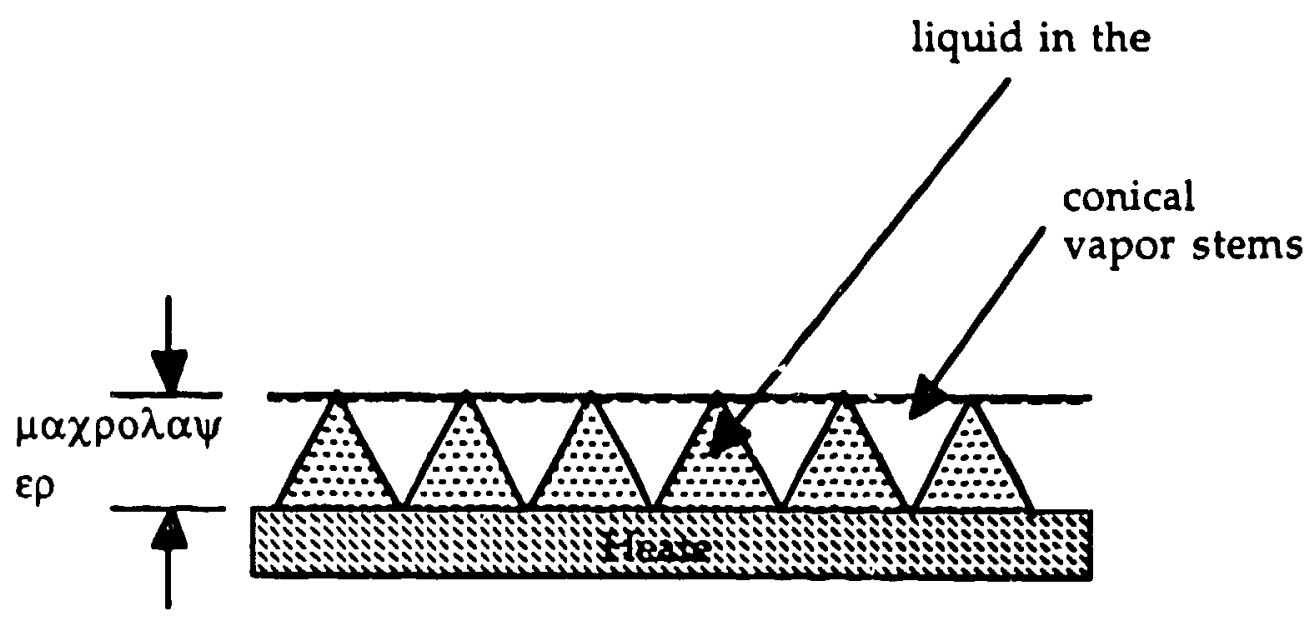

Fig. 3.

Bhat et al.'s (1983) model for the macrolayer. 

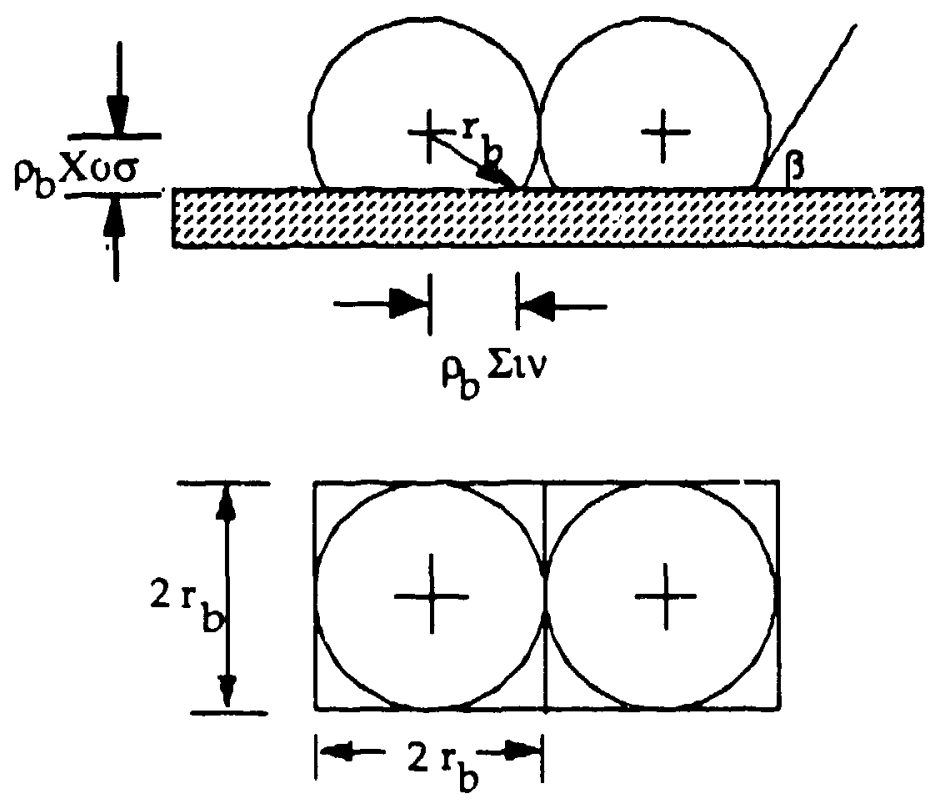

Fig. 4a.

Idealized sketch of vapor bubbles growing at uniformly distributed cavities.

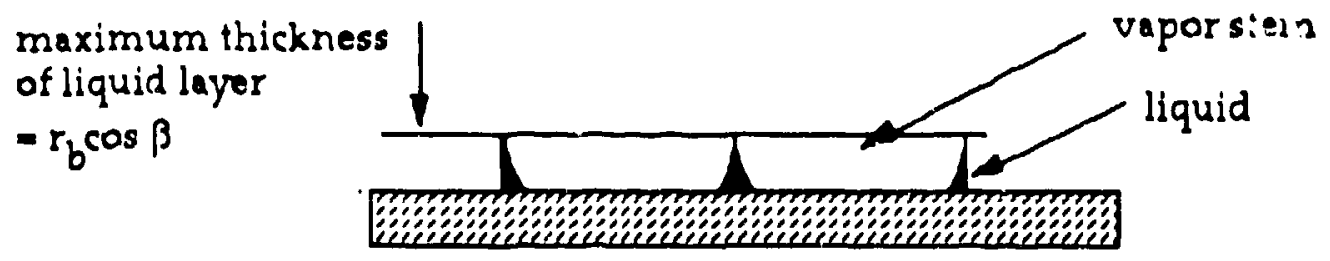

Fig. 4b.

Idealized sketch of the macrolayer formed after coalescence of neighboring bubbles. 


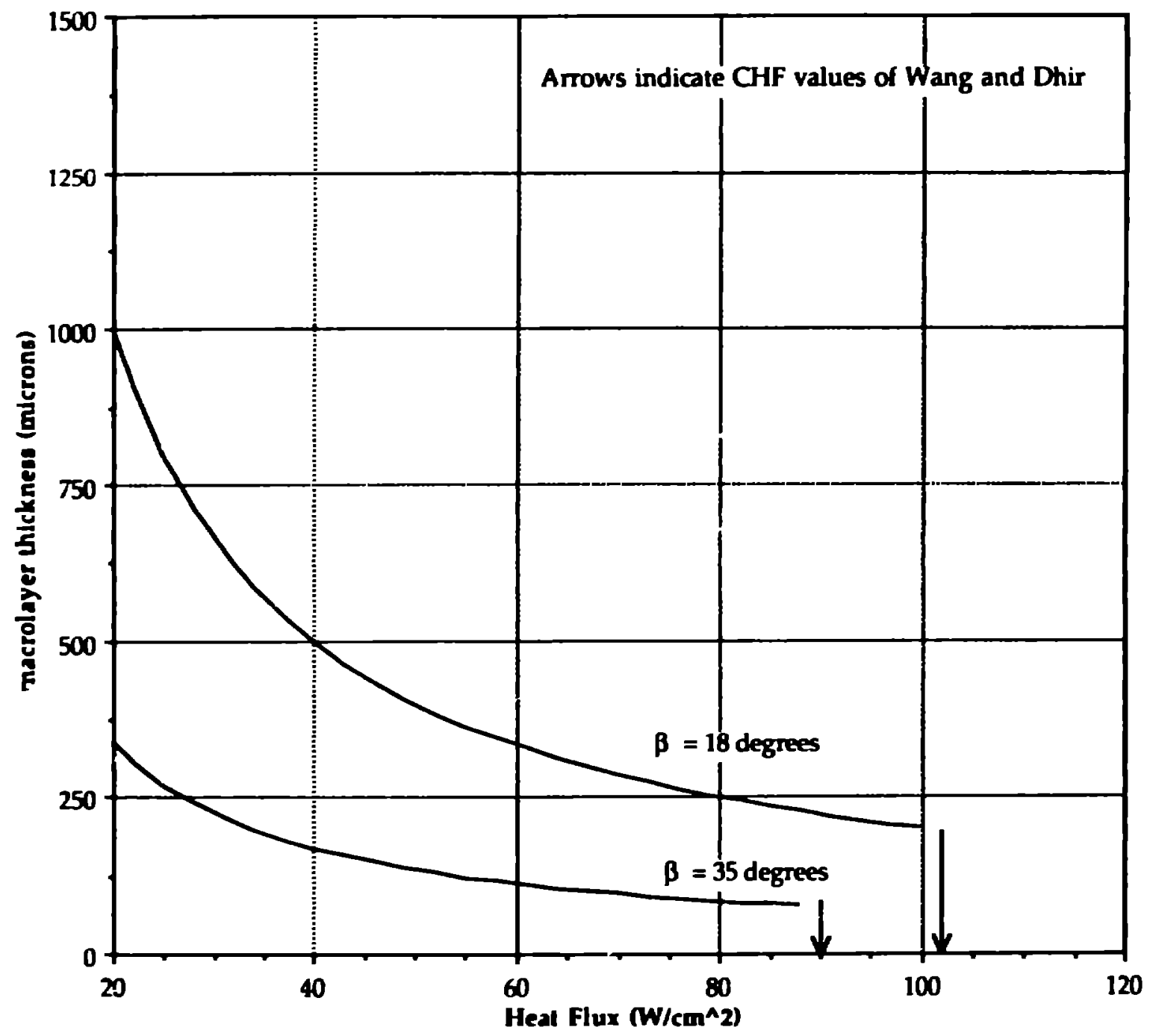

Fig. 5.

Plot of calculated macrolayer thickness versus heat flux for contact angles of $35^{\circ}$ and $18^{\circ}$. 


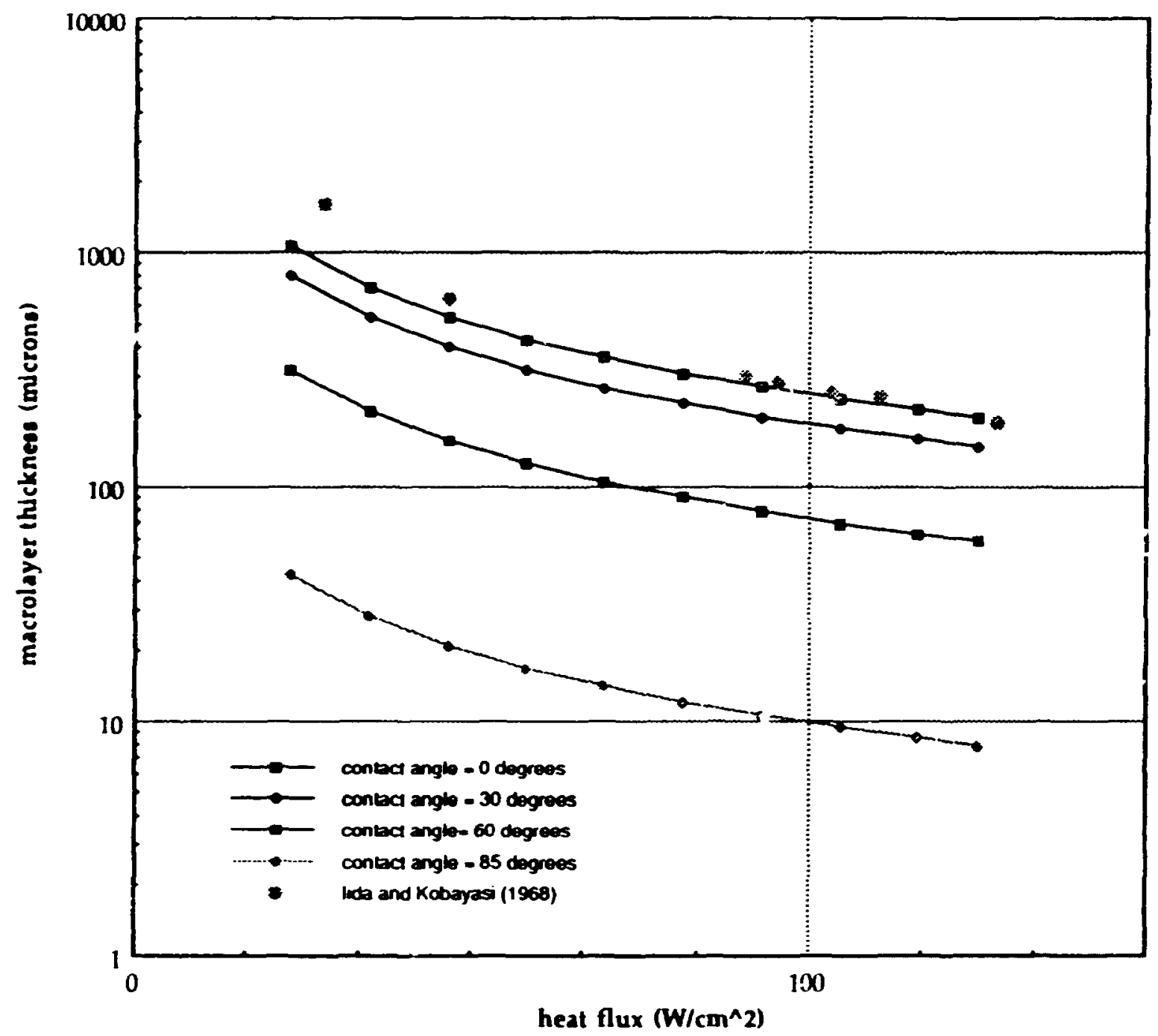

Fig. 6.

Comparison of predicted macrolayer thicknesses with average thickness measurements of lida and Kobayasi (1969). 